NASA Technical Memorandum 4597

\title{
Transonic Flight Test of a Laminar Flow Leading Edge With Surface Excrescences
}

Fanny A. Zuniga

Dryden Flight Research Center

Edwards, California

Aaron Drake

Stanford University

Robert A. Kennelly, Jr.

Dennis J. Koga

Ames Research Center

Russell V. Westphal

Washington State University at Tri-Cities

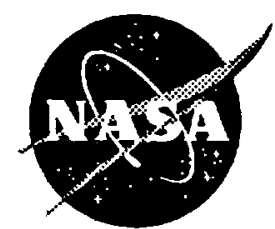

National Aeronautics and

Space Administration

Office of Management

Scientific and Technical

Information Program 


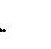




\title{
TRANSONIC FLIGHT TEST OF A LAMINAR FLOW LEADING EDGE WITH SURFACE EXCRESCENCES
}

\author{
Fanny A. Zuniga" \\ NASA Dryden Flight Research Center \\ P. O. Box 273 \\ Edwards, CA 93523-0273 \\ Aaron Drake ${ }^{b}$ \\ Stanford University \\ Robert A. Kennelly, Jr." \\ Dennis J. Koga ${ }^{\complement}$ \\ NASA Ames Research Center \\ Russell V. Westphal \\ Washington State University at Tri-Cities
}

\begin{abstract}
A flight experiment, conducted at NASA Dryden Flight Research Center, investigated the effects of surface excrescences, specifically gaps and steps, on boundary-layer transition in the vicinity of a leading edge at transonic flight conditions. A natural laminar flow leading-edge model was designed for this experiment with a spanwise slot manufactured into the leading-edge model to simulate gaps and steps like those present at skin joints of small transonic aircraft wings. The leading-edge model was flown with the flight test fixture, a low-aspect ratio fin mounted beneath an F-104G aircraft. Test points were obtained over a unit Reynolds-number range of 1.5- to 2.5-million/ft and a Mach-number range of 0.5 to 0.8 . Results for a smooth surface showed that laminar flow extended to approximately $12 \mathrm{in}$. behind the leading edge at Mach number 0.7 over a unit Reynolds-number range of 1.5- to 2.0-million/ft. The maximum size of the gap-andstep configuration over which laminar flow was maintained consisted of two 0.06 -in. gaps with a 0.02-in. step at a unit Reynolds number of 1.5 million/ $\mathrm{ft}$.
\end{abstract}

\section{Nomenclature}

FTF

flight test fixture

HLFC

hybrid laminar flow control

"Aerospace Engineer. AIAA Member.

bGraduale student. AIAA Member.

senior Research Scientist. AIAA Member.

dAssocinte Professor. AIAA Member.

Copyright O 1994 by the American Institute of Aeronautics and Astronautics, Inc. No copyright is asserted in the Unized States under Title 17, U.S. Code. The U.S. Govemment has a royalty-free license to exercise all rights under the copyright claimed herein for Govemmental purposes. All other rights are reserved by the copyright owner.

\section{NACA National Advisory Committee for} Aeronautics

NASA National Aeronautics and Space Administration

NLF natural laminar flow

$C_{f}$

skin-friction coefficient, $\frac{\tau}{\frac{1}{2} \rho U_{\infty}^{2}}$

C

coefficient of pressure, $\frac{P-P_{\infty}}{q_{\infty}}$

chord of the NLF leading-edge model, in.

Stanton gauge height, $\mathrm{ft}$

local static pressure along the chord of the FTF, lb/ft ${ }^{2}$

free-stream static pressure, $\mathrm{lb} / \mathrm{ft}^{2}$

free-stream dynamic pressure, $\mathrm{lb} / \mathrm{ft}^{2}$

$q_{\infty}$

$\mathrm{Re} / \mathrm{ft}$

$\mathrm{Re}_{\mathrm{v}}$

$s$

$U_{\infty} \quad$ free-stream velocity, $\mathrm{f} / \mathrm{sec}$

$\boldsymbol{x}$

longitudinal or chordwise distance from nose leading edge, in.

lateral distance from leading-edge model centerline, in. 
vertical FTF spanwise distance from root, in.

$$
\text { Stanton gauge pressure difference, } \mathrm{lb} / \mathrm{ft}^{2}
$$

viscosity coefficient at free-stream conditions, $\mathrm{lb} / \mathrm{ft} \cdot \mathrm{sec}$

density of flow at free-stream conditions, slug/ $/ \mathrm{t}^{3}$

shearing stress, $\mathrm{lb} / \mathrm{ft}^{2}$

\section{Introduction}

The recent resurgence of interest in using laminar flow on aircraft surfaces for reduction in skin-friction drag has generated a considerable amount of research in natural laminar flow (NLF) and hybrid laminar flow control (HLFC) on transonic aircraft wings. This research has focused primarily on airfoil design and understanding transition behavior with less concern for the surface imperfections and manufacturing variations inherent to most production aircraft. ${ }^{1}$ Well-defined criteria for allowable sizes of gaps and steps that result from aircraft skin seams, as well as criteria for rivet and fastener sizes are essential if NLF/HLFC technology is to be used on massproduced aircraft.

Three basic types of surface imperfections are responsible for prematurely tripping the boundary layer from laminar to turbulent: (1) surface waviness, (2) twodimensional spanwise roughness elements such as gaps and steps at seams; and (3) three-dimensional roughness elements such as protruding fasteners and insect remains. Criteria exist for each of these cases where transition is caused by amplification of the Tollmien-Schlichting waves or laminar boundary-layer separation. ${ }^{2}$

For the case of modem light transonic aircraft, the surface waviness is generally believed to be within accepted limits. From the work of B. H. Carmichael, ${ }^{3}$ the allowable waviness is a function of Reynolds number, wing chord, and wing leading edge sweep. For a typical business jet at cruise conditions with a leading-edge sweep of $15^{\circ}$, for example, the allowable amplitude is approximately 0.02 in. for a 2 -in. wavelength.

Two-dimensional roughness elements, however, do pose a problem since most business jet wings are constructed with a spanwise joint between the leading-edge skin piece and the main wing skin approximately 4 to 6 in. downstream of the leading edge. The resulting gaps and steps are believed to cause transition under all conditions. Wind-tunnel results for a flat plate give a critical Reynolds number based on step height or gap width for various geometries. ${ }^{4}$ For the case of Mach 0.7 and Re/ft of 1.5 million, these critical Reynolds numbers translate to allowable square step heights of approximately 0.014 in., and gap widths of 0.12 in. Note that elements with rounded corners are reported to have higher critical Reynolds numbers than similar geometries with angled corners. ${ }^{2}$

An experiment was conducted to provide an in-flight investigation as to the effects of these spanwise steps and gaps on the laminar boundary layer near the leading edge of a transonic wing. A flight experiment was desired since experimental determination of surface quality requirements conducted in a wind tunnel would be subject to poorly understood turbulence effects. The F-104 flight test fixture (FTF), ${ }^{5}$ was ideally suited for this experiment and was selected as the test facility. The size of the FTF allowed for full-scale testing directly applicable to business jets and light transports. Furthermore, the flight envelope of the F-104/FTF allowed for speed, altitude, Mach number, Reynolds number, and any atmospheric effects at transonic flight conditions to be duplicated.

\section{Test Hardware Description}

A new leading-edge model was specially designed to fly on the F-104/FTF. The FTF is a unique test facility for conducting aerodynamic and fluid-mechanic experiments. Its experiments are self-contained within the fixture and independent of the aircraft systems. The overall dimensions of the FTF consists of a chord length of 81 in., a span of 24 in., and for the major part of its length, except the forebody, the thickness is a constant 6.4 in. Figure 1 shows an aerial photograph of the FTF mounted vertically on the lower centerline of the F-104G carrier aircraft. A detailed description of the FTF, its capabilities, and its flow qualities underneath the F-104 aircraft $c a n$ be found in reference 5 .

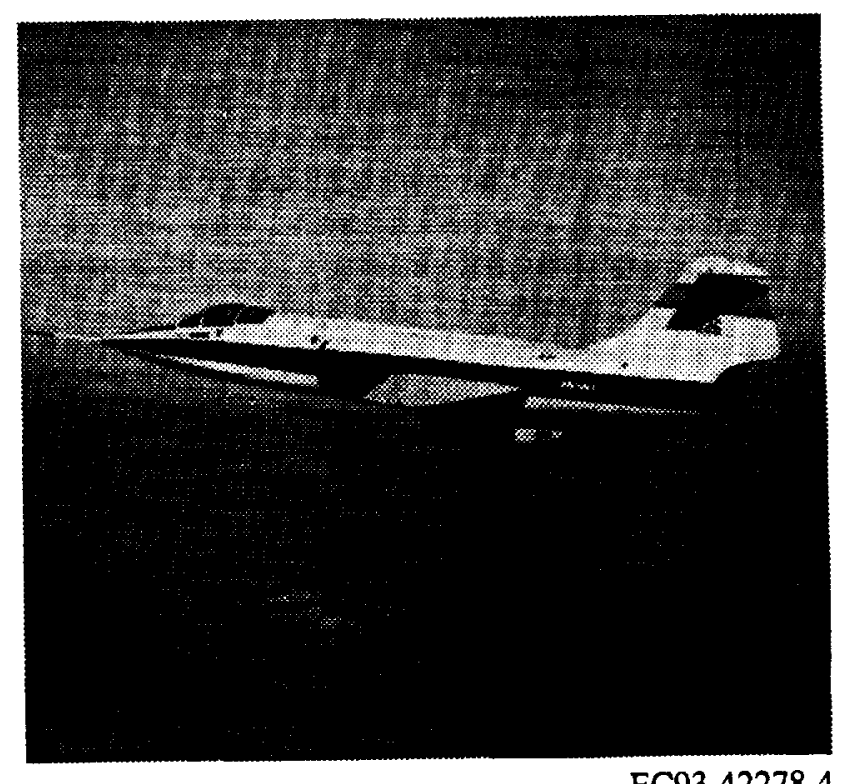

(a) F-104 in flight.

Figure 1. Flight test fixture mounted on F-104 aircraft. 


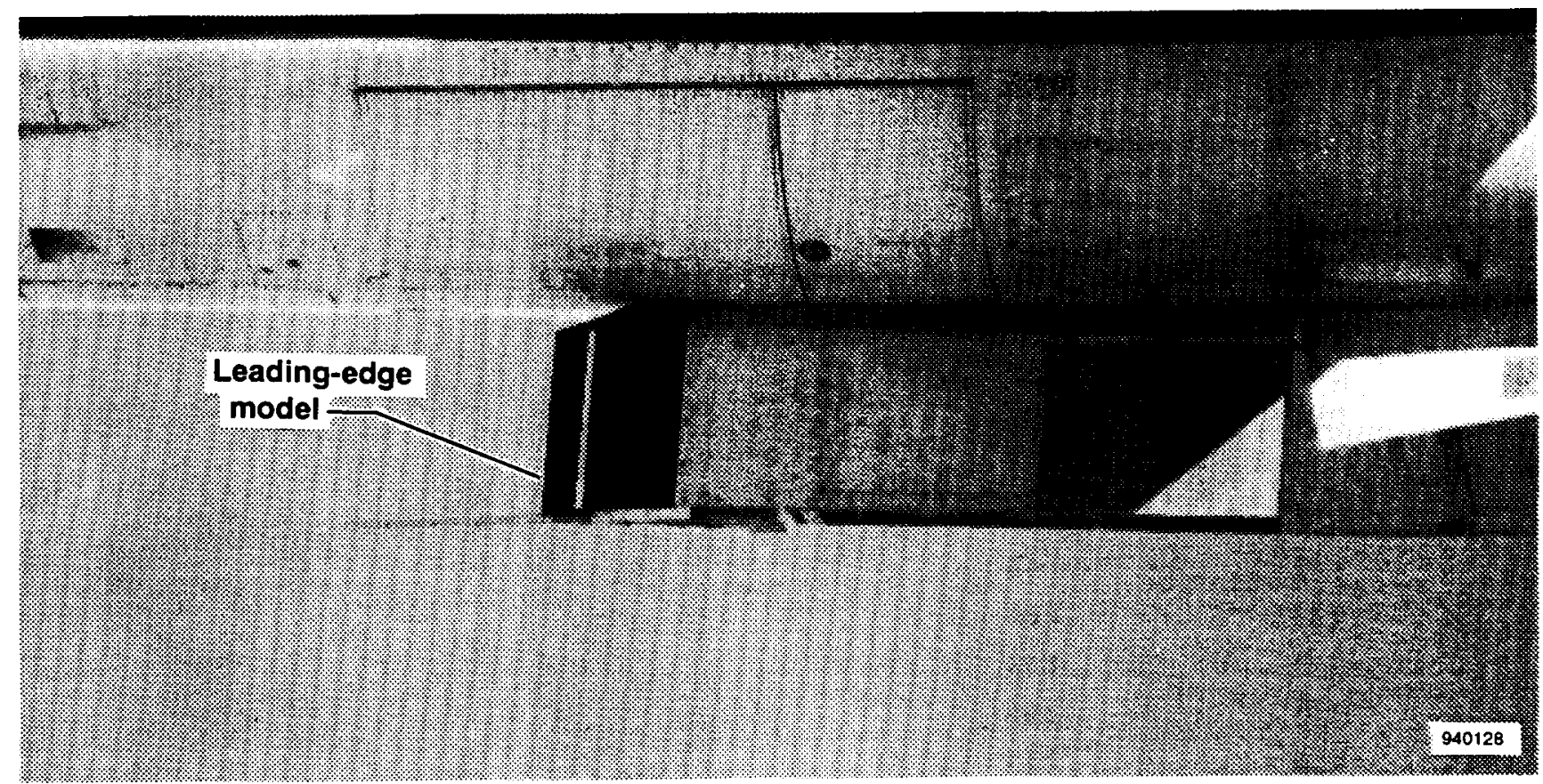

(b) Closeup of fixture.

Figure 1. Concluded.

The leading-edge model was designed to produce natural laminar flow over its full length at transonic flight conditions. The model was constructed of foam-core fiberglass. The overall length of the symmetrical leadingedge model was 15.27 in., its thickness at the base was 6.75 in. and its height was 21.75 in. Figure 2 shows the overall dimensions and cross-section of the model and table 1 lists the cross-section's $x$ - and $y$-coordinates.

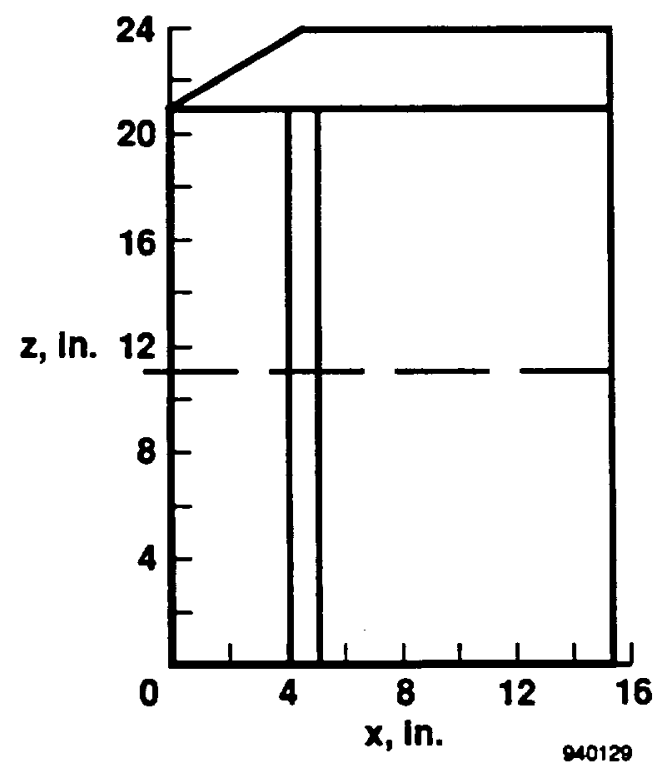

(a) Overall dimensions.
Surface quality requirements for the leading-edge model were based on work done by B. H. Carmichael. ${ }^{3}$ The tolerances of the cross-sectional dimensions were kept to within \pm 0.03 in. The maximum surface waviness height for the model was kept to within 0.001 in. per 2 in., the maximum roughness was 25 microns and the surface point accuracy was \pm 0.03 in.

A spanwise slot was manufactured into the left side of the leading-edge model 4 in. behind the leading edge. This slot was 1.0 in. wide and 0.12 in. deep and ran along the entire span of the model. The fiberglass corners of the slot were manufactured sharp enough to simulate edges of aluminum aircraft skin. To strengthen the slot, an aluminum strip was milled and embedded in the fiberglass and

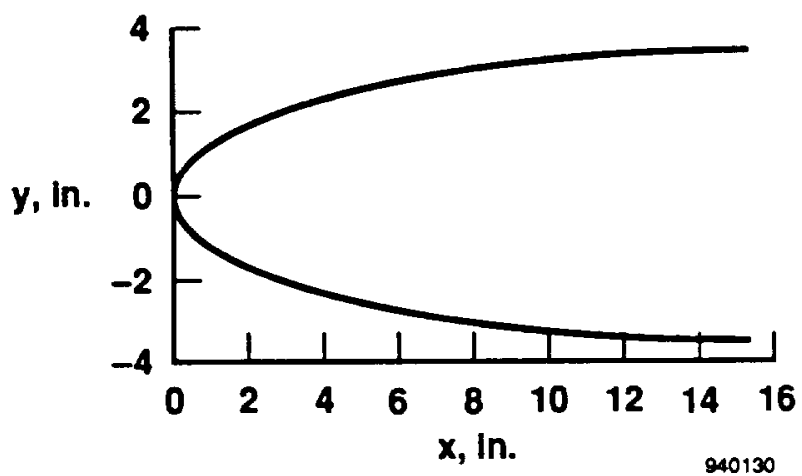

(b) Cross-section dimensions.

Figure 2. The NLF leading-edge model. 
Table 1. Coordinates of a cross-section of the leadingedge model.

\begin{tabular}{cc}
\hline \hline$x$ (in.) & $y$ (in.) \\
\hline 0.00 & 0.00 \\
0.06 & 0.26 \\
0.23 & 0.50 \\
0.41 & 0.67 \\
0.64 & 0.84 \\
0.97 & 1.04 \\
1.38 & 1.23 \\
1.82 & 1.42 \\
2.34 & 1.60 \\
2.91 & 1.78 \\
3.55 & 1.96 \\
4.24 & 2.13 \\
6.67 & 2.62 \\
8.56 & 2.90 \\
10.62 & 3.14 \\
12.86 & 3.30 \\
15.27 & 3.37 \\
\hline \hline
\end{tabular}

formed the lower face of the slot. Finally, the model was painted flat black with a gel coat surface. Figure 3 shows the finished leading-edge model.

\section{Instrumentation}

Figure 4 shows the experiment setup for both sides of the leading-edge model. The left side (fig. 4(a)) of the model is the control side where different gap and step combinations were configured. The right side (fig. 4(b)) was kept completely smooth except for the row of flush surface pressure orifices. The instrumentation consisted of 5 hot-film sensors, 4 Stanton gauges, and 24 static pressure taps. All research and airdata parameters, except the hot-film signals, were digitally encoded using pulse code modulation, and were recorded simultaneously on board and telemetered to ground-base recorders.

A hot-film system was used to ascertain the state of the boundary layer. The hot-film system consisted of singleelement hot-film sensors and constant-temperature anemometer cards that were developed at NASA Dryden. 6 The hot-film data were recorded on board using a frequency modulation recorder and had a frequency response of $10 \mathrm{kHz}$. The hot films were positioned in such a way as to minimize any flow disturbance between sensors. Table 2 lists their $x$-and $y$-locations.

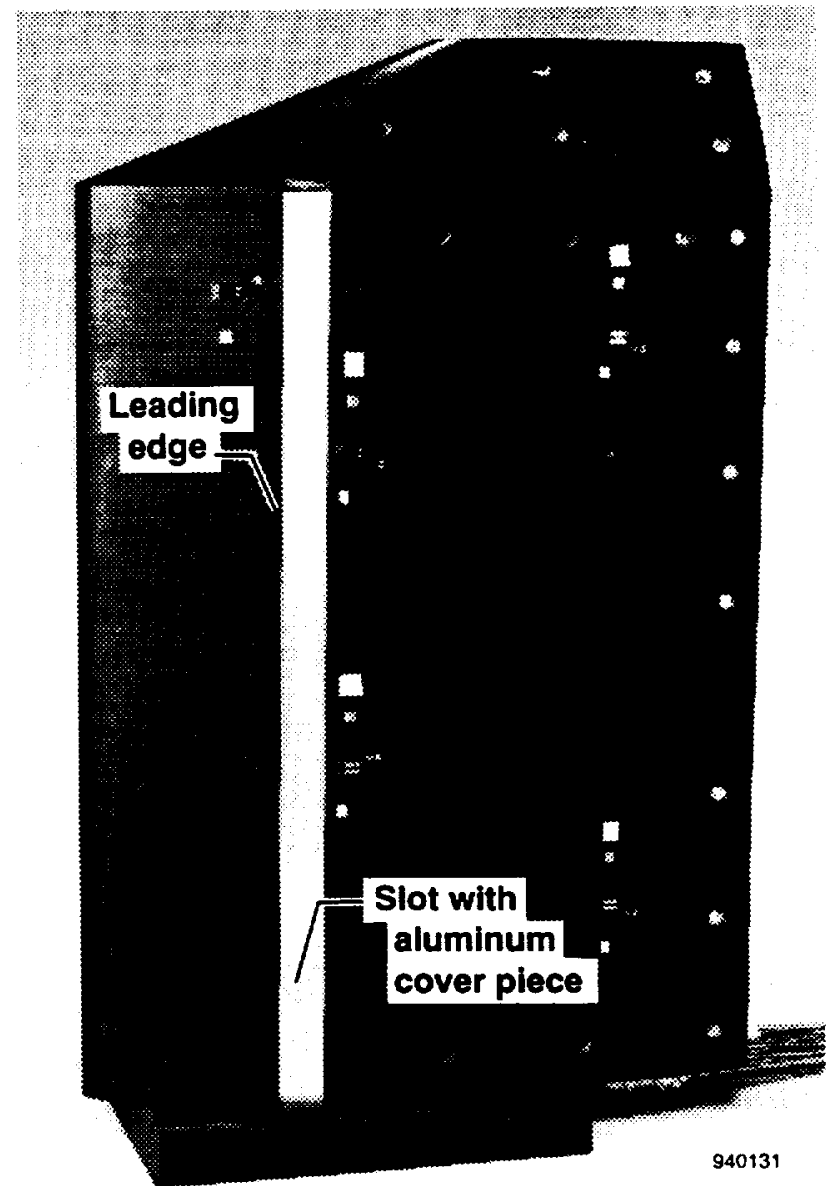

Figure 3. NLF leading-edge model with instrumentation.

Hot-fllm sensor

- Stanton gauge

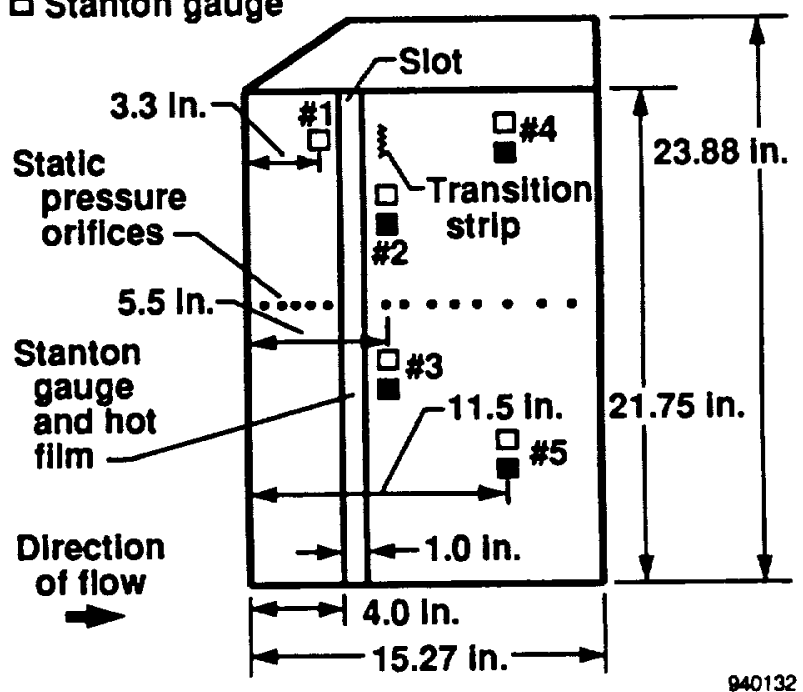

(a) Left side.

Figure 4. Experiment setup of NLF leading-edge model. 


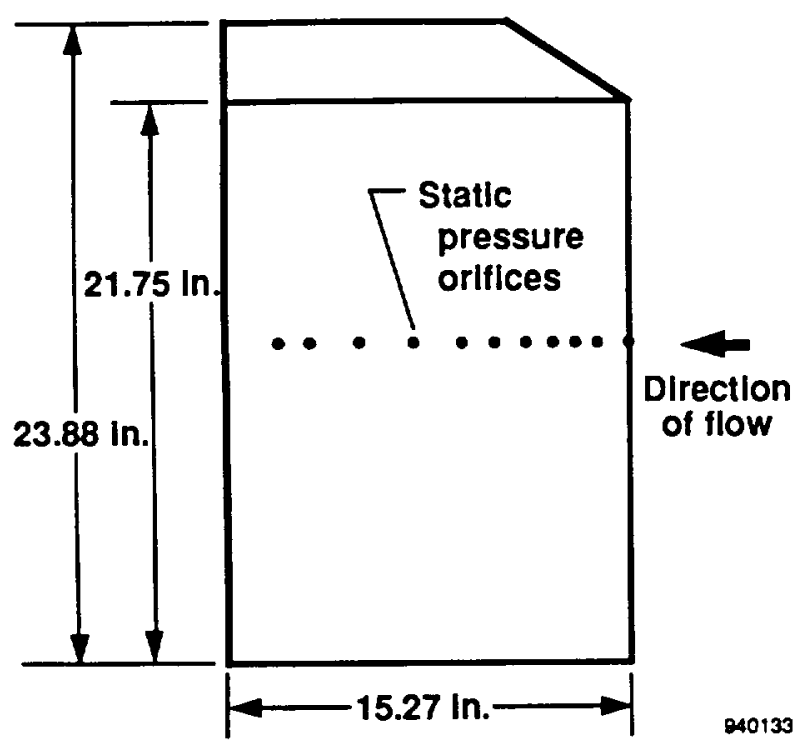

(b) Right side.

Figure 4. Concluded.

Table 2. Hot-film locations for the NLF leading-edge model.

\begin{tabular}{ccr}
\hline \hline No. & $x$ (in.) & $z$ (in.) \\
\hline 1 & 3.3 & 5.63 \\
2 & 5.5 & 8.13 \\
3 & 5.5 & 15.13 \\
4 & 11.5 & 5.63 \\
5 & 11.5 & 18.63 \\
\hline \hline
\end{tabular}

Figure 5 shows a hot-film sensor positioned adjacent to a Stanton gauge. The Stanton gauge provided a relatively inexpensive and effective method for measuring local skin friction.' The Stanton gauge consists of a segment of razor blade mounted over a flush pressure orifice. Static pressures needed to calculate skin friction were obtained from adjacent flush pressure orifices. As shown in the figure inset, the blade faces directly upstream, and the tip is aligned directly over the forward most lip of the static pressure orifice. The distance from the surface to the tip of the razor blade, or gauge height, $h$, is approximately 0.005 in. In addition, the width of the razor blade is 0.25 in., which is sufficiently wide enough to minimize any disturbances from the open sides.

The differential pressures between the total and static lines of each gauge were measured with $a \pm 1-1 b / i^{2}$ differential pressure transducer except for Stanton gauge no. 2 .

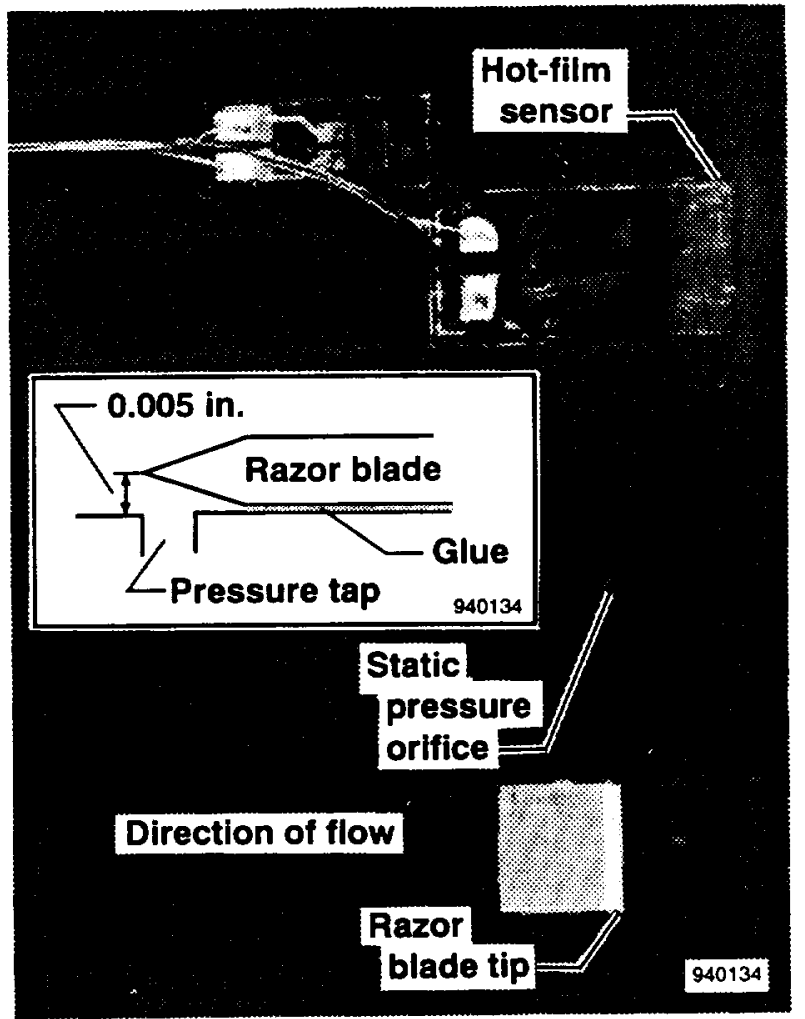

Figure 5. Hot-film and Stanton-gauge sensors mounted on NLF model.

The total and static pressures from this gauge were measured with $\pm 10-\mathrm{lb} / \mathrm{in}^{2}$ electronic scanning pressure modules. The data from Stanton gauge no. 3 were not used because of a malfunction in that pressure transducer.

A row of flush static pressure orifices positioned along the midspan of each side of the leading-edge model was used to determine the pressure distributions. The right side consisted of 10 pressure orifices and the left side consisted of 13 pressure orifices with 1 pressure orifice positioned exactly at the leading edge. Table 3 lists the chordwise orifice locations of the pressure orifices for both the right and left sides of the model.

Surface static pressures were measured with $\pm 10-\mathrm{lb} / \mathrm{in}^{2}$ electronic scanning pressure modules. All flush static pressure orifices including those from the Stanton gauge had an inside diameter of 0.03 in. Data from all the pressures were recorded at 7.8 samples/sec.

In addition to the aircraft's standard NACA noseboom, the FTF was also instrumented with a noseboom that provided an independent measurement of Mach number, dynamic pressure, and altitude. This FTF airdata were used throughout the data analysis and are presented in the results. 
Table 3. Locations of chordwise static pressure orifices on the leading-edge model.

\begin{tabular}{ccc}
\hline $\begin{array}{c}x \text { (in.) } \\
\text { (Left side) }\end{array}$ & No. & $\begin{array}{c}x \text { (in.) } \\
\text { (Right side) }\end{array}$ \\
\hline 0.5 & 1 & 1.0 \\
1.0 & 2 & 2.5 \\
1.75 & 3 & 3.5 \\
2.5 & 4 & 4.5 \\
3.5 & 5 & 5.5 \\
5.5 & 6 & 6.5 \\
6.5 & 7 & 8.5 \\
8.0 & 8 & 10.75 \\
9.0 & 9 & 12.75 \\
10.25 & 10 & 14.0 \\
11.5 & 11 & n.a. \\
12.75 & 12 & n.a. \\
14.0 & 13 & n.a. \\
\hline \hline
\end{tabular}

\section{Flight Test Conditions and Procedures}

Figure 6 shows all test points obtained during the flight experiment along with the flight envelope of the F-104/FTF. The Mach numbers ranged from 0.5 to 0.8 and unit Reynolds numbers ranged from 1.5 - to 2.5 -million/ft. Although the leading-edge model was specially designed for subsonic test conditions, some supersonic test conditions were obtained as shown in the figure. The results of the supersonic cases will not be discussed in this paper.

The pilot flew all test points at steady-state flight test conditions using an uplink trajectory guidance system. ${ }^{8}$

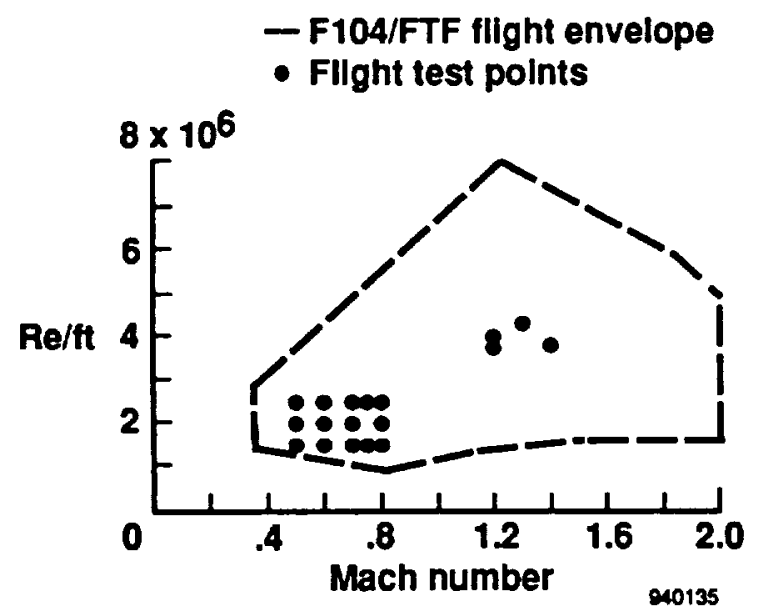

Figure 6. F-104/FTF fight envelope including flight test points.

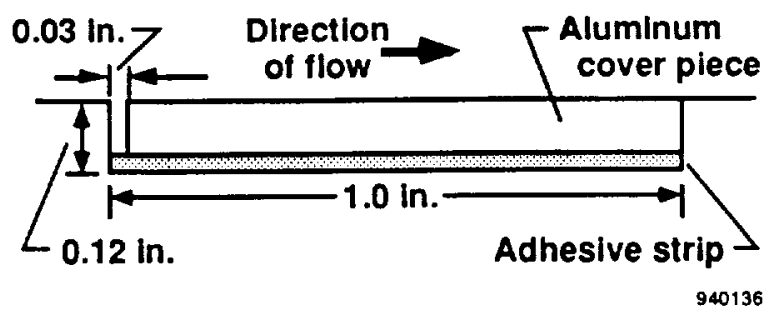

(a) With 0.03 in. forward gap.

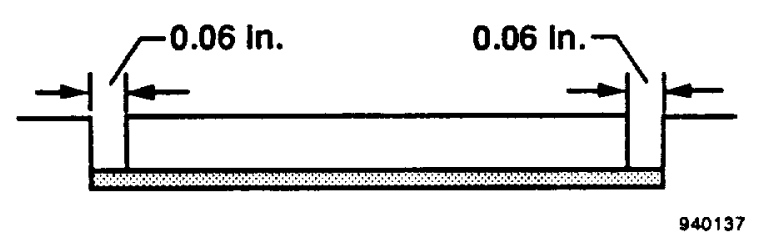

(b) With 0.06 in. forward and aft gaps.

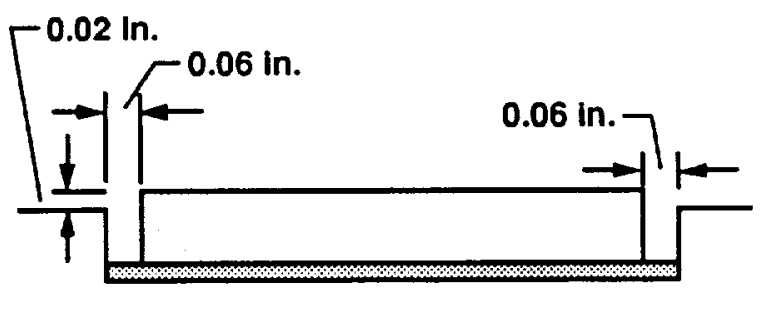

(c) With 0.06 in. forward and aft gaps with 0.02 in. step.

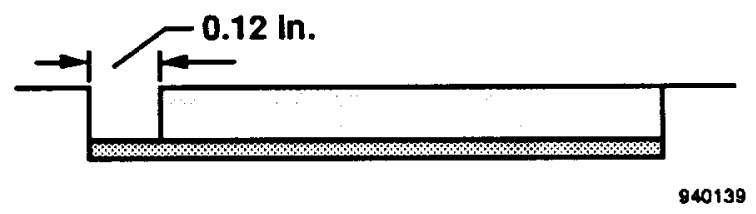

(d) With 0.12 in. forward gap with sharp leading edge.

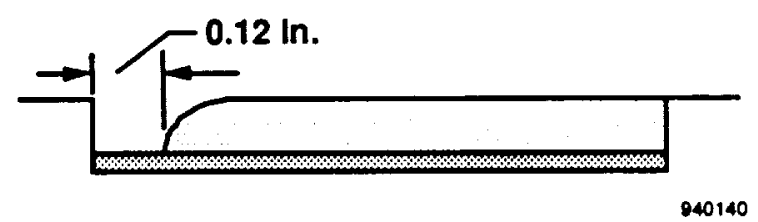

(e) With 0.12 in. forward gap with rounded leading edge.

Figure 7. Step and gap configurations in the NLF model slot.

This uplink system indicated differences between desired and actual flight conditions, specifically Mach number, altitude, and angle of sideslip. This system was used to reduce the pilot's workload and ensure the accuracy and repeatability of the data. 
The subsonic test points were repeated for each configuration. Five step-gap configurations were tested and are shown in figure 7. As shown in this figure, by altering the size of the aluminum cover piece inserted in the slot of the leading-edge model, the size of the gaps and step were controlled with high precision. After each installment of the cover piece, the gaps and step were measured with a micrometer and depth gauge and were within 0.005 in. of the desired value for all cases.

The aluminum cover piece was installed in the slot using a two-sided, adhesive-backed, foam tape that held firmly in place throughout the flight. The cover piece and tape were then removed and replaced for the next flight.

\section{Results and Discussion}

At the present time (March 1994), flight tests have recently concluded and preliminary results for three configurations at selected flight conditions will be presented here. More detailed analyses of the data from the flight tests are in progress.

\section{Design of Leading-Edge Model}

The primary design objective of the leading-edge model was to provide a laminar boundary layer over most of the surface area of the model. In a process similar to that used in designing an NLF airfoil, a shape was sought that would result in a favorable chordwise pressure gradient with its peak as rearward as possible. In this way, the flow over the leading-edge region of an NLF wing was simulated over the model attached to the FTF.

Additionally, it was desired that the sensitivity of the design to small changes in angle of attack be minimized. Angle of attack on the FTF corresponded to aircraft sideslip. To allow for variations in aircraft sideslip, a pressure distribution was sought to remain well-behaved up to $\pm 1.5^{\circ}$ angle of attack on the FTF.

The final design resulted in a favorable pressure gradient that extended to 80 percent of the leading-edge model length for a Mach number range of 0.5 to 0.8. A twodimensional inviscid, full potential computational fluid dynamics code, known as FLO6SD, ? was used to predict the pressure distributions. Figure 8 shows the predicted pressure distribution for Mach 0.7. This pressure gradient remained favorable throughout an angle-of-attack range of $-1.5^{\circ}$ to $1.5^{\circ}$.

Figure 8 also shows the flight-determined pressure distributions for the left and right sides of the leading-edge model. As can be seen from this figure, there was good agreement between the predicted and flight-determined pressure distributions.

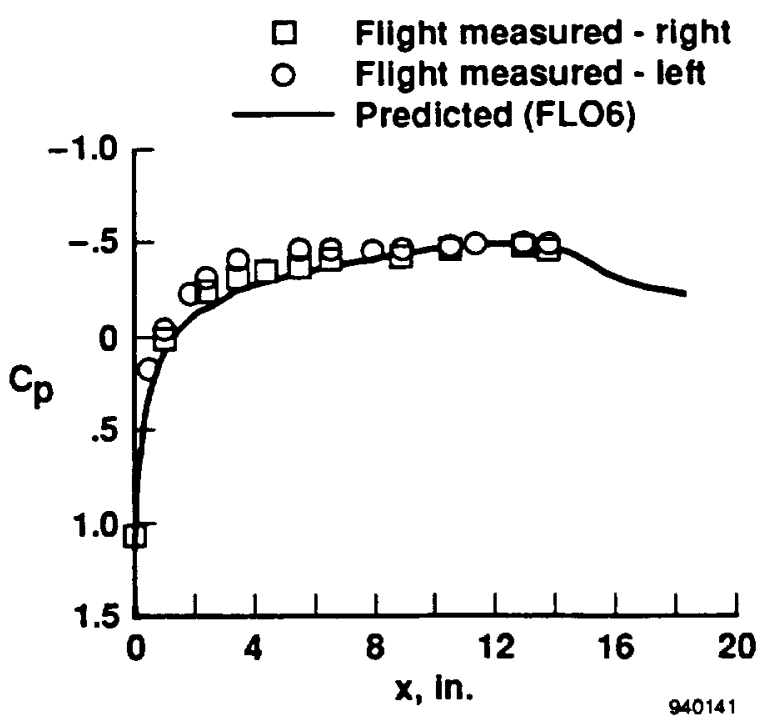

Figure 8. Comparison of predicted and flight-determined pressure distribution for $M=0.7$.

\section{Boundary-Layer Transition Measurement Methods}

Two techniques were used for detecting boundary-layer transition. The first of these techniques used hot-film sensors. By examining the fluctuating or high-frequency signals from these sensors, the state of the boundary layer was determined. Figure 9 shows examples of time histories from the hot-film sensors illustrating the four typical indications of these signals-that is, laminar, intermittent, transitional and turbulent flows. Also, the average or rootmean-square values of these high-frequency signals were computed to aid in interpreting these signals.

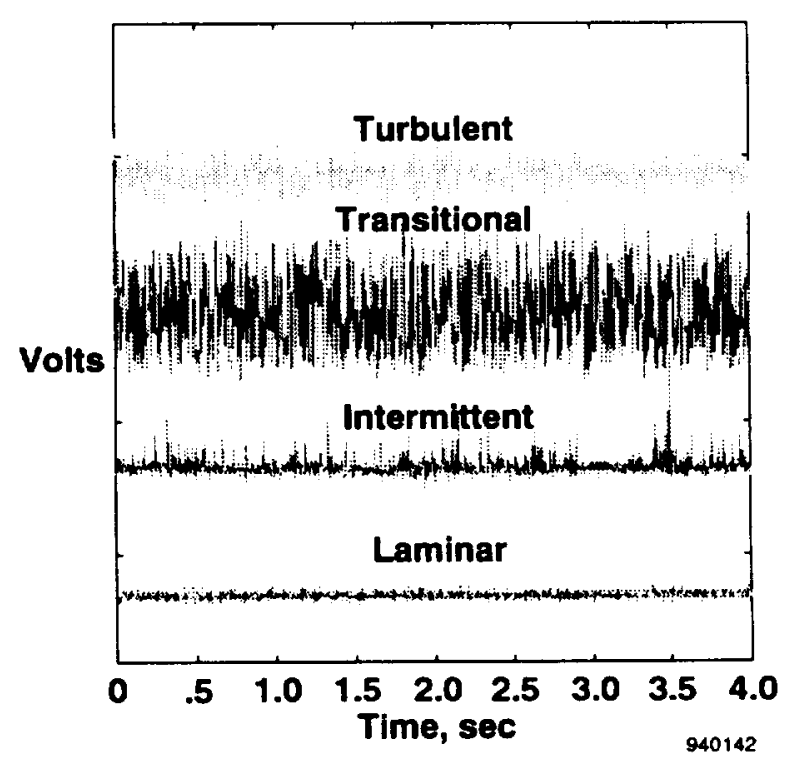

Figure 9. Examples of hot-film time histories. 
In addition, hot films nos. 1 and 4, as shown in figure 4, were used as reference signals. Hot film no. 1 was positioned upstream of the slot in a very favorable pressure gradient and its signal was used as a reference for a laminar flow signal. Similarly, hot film no. 4 was positioned behind a transition strip so that its signal could be used as a reference for a turbulent flow signal.

Stanton gauges were also used for detecting boundarylayer transition. The gauges were positioned adjacent to hot films nos. 2 through 5. By measuring the local skin friction, they also provided an indication of laminar or turbulent flow. Skin-friction measurements were obtained by taking the difference between the total pressure and the adjacent local static pressure. This pressure difference $(\Delta P)$ was then related to the local skin-friction coefficient, $C_{f}$, through East's calibration.?

This calibration was made in a low-speed, turbulent, zero-pressure gradient boundary layer. Even though the calibration was made in a turbulent boundary layer, as long as the razor blade is sized correctly, it should be accurate to 10 or 20 percent in laminar boundary layers.

The gauge height was chosen so that the edge of the blade lay within the lower part of the boundary layer where the velocity profile is nearly linear for both laminar and turbulent boundary layers. The gauge height used in this experiment, that is, the height between the surface and the tip of the razor blade, was $0.005 \mathrm{in}$.

Once the local skin-friction coefficient, $C_{f}$, was determined it was used with the results of the boundary-layer analysis to determine the state of the boundary layer at each gauge location. The boundary-layer analysis was conducted using a code named IBL." The key assumption made in running IBL was that it used the FLO6 pressure distributions as input.

Figure 10 illustrates the procedure used to determine the state of the boundary layer. For Mach 0.7 and Re/ft 1.5 million, $C_{f}$ was first determined using the calibration curve of figure $10(\mathrm{a})$. Then, this $C_{\text {f value was plotted, as }}$ shown in figure 10(b), which contains the results of the IBL boundary-layer run for that flight condition. If the point was on or above the dashed turbulent line, the flow was identified as turbulent. If the point was on or near $( \pm 15$ percent) the solid laminar line, the flow was identified as laminar. If the point was in the region between either line, the flow was identified as transitional.

\section{Results for a Single-Gap Configuration}

The first configuration consisted of a single 0.03 -in. gap set 4 in. behind the leading edge. Figures 11 (a) and $11(\mathrm{~b})$ show the state of the boundary layer at each of the hot-film and Stanton-gauge locations for Mach number of 0.7 and unit Reynolds numbers of $1.5-, 2.0$, and $2.5-\mathrm{million} / \mathrm{ft}$.

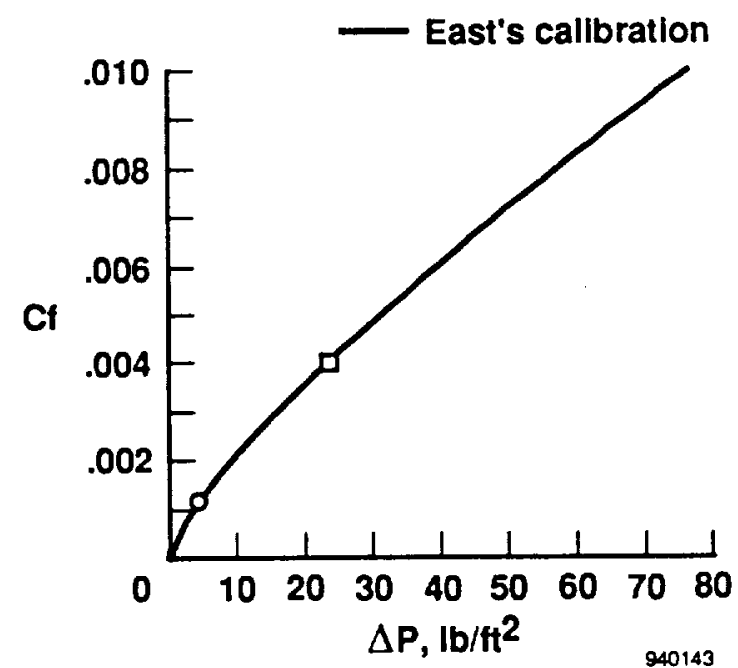

(a) Calibration.

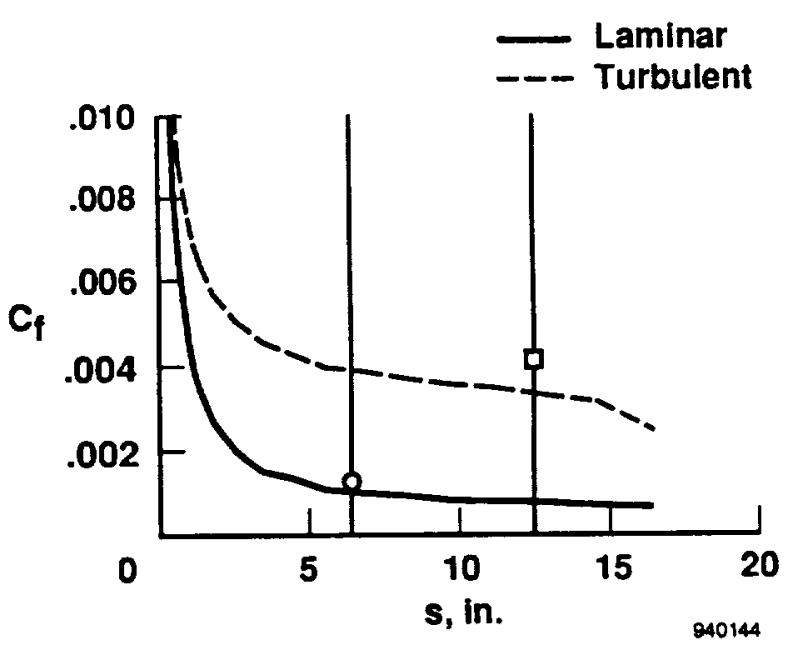

(b) Predicted skin friction.

Figure 10. Example of Stanton-gauge data analysis for $M=0.7$ and $\mathrm{Re} / \mathrm{ft}=1.5$ million.

The open symbols in the figures represent the results from the hot-film data analysis and the closed symbols represent the results from the Stanton-gauge data analysis. Laminar flow was maintained over the gap and extended to about 75-percent chord or the location of hot film no. 5 at unit Reynolds number of 1.5- and 2.0-million/ft (fig. 11(a)).

In general, the results from the Stanton gauges were in agreement with the results from the hot films. For unit Reynolds numbers of 1.5 - and 2.0 -million/ft, however, there was disagreement between Stanton gauge no. 5 and hot film no. 5. Skin-friction measurements from this Stanton gauge indicated a laminar boundary layer, while turbulent flow was detected by hot film no. 5. The configuration was flown again at repeated flight conditions: the same results occurred. 


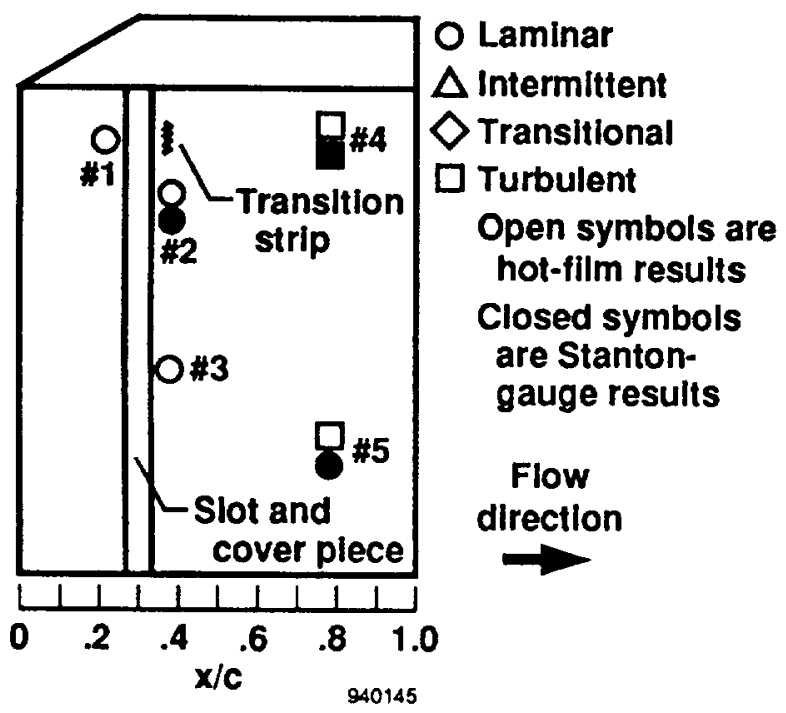

(a) $\mathrm{Re} / \mathrm{ft}=1.5$ and 2.0 million.

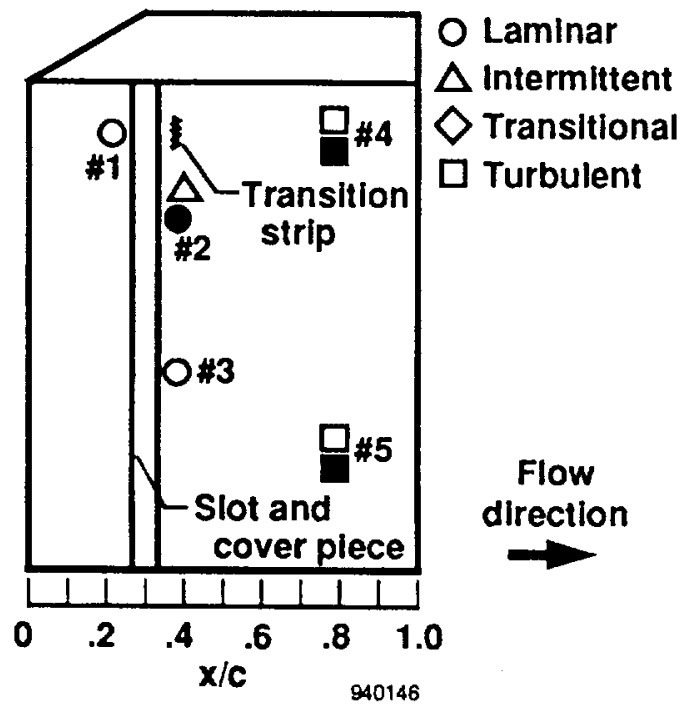

(b) $\mathrm{Re} / \mathrm{ft}=2.5$ million.

Figure 11. Boundary-layer state results for 0.03 -in. gap configuration at $M=0.7$.

One reason for the difference in the results may be the small difference in spanwise location between the two sensors. Since transition often occurs in turbulent wedges, one of the sensors may have been downstream of a turbulent wedge and the other sensor may have been outside of it, in the laminar flow. Therefore, to determine the extent of laminar flow for this configuration, shear-sensitive liquid crystals were used as a flow diagnostic tool.

The use of shear-sensitive liquid crystals as a technique for detccting boundary-layer transition is described in refcrence 12 . Basically, the crystals respond to changes in surface shear stress by altering the color "seen" from a fixed observation point. Figure 12 shows an in-flight photograph of the right side of the leading-edge model with the liquid crystals coating at Mach 0.7 and $\mathrm{Re} / \mathrm{ft} 2.0$ million. As can be seen from the figure, a few turbulent wedges occurred at this flight condition. Only the upper half of the leading-edge model remained mostly free of these wedges and laminar flow can be seen extending to the aft end of the model by the uniform color in this area. Since these wedges remained in the same location throughout most of the flight, they do not seem to indicate naturally occurring transition but appear to result from surface irregularities. The results of the left, instrumented side were not as clear because the instrumentation was interfering with the flow. Nevertheless, it is likely that turbulent wedges may be occurring on the instrumented side and are the reason that Stanton gauge no. 5 and hot film no. 5 appear to be giving opposing results. In any case, the results from Stanton gauge no. 5 at this flight condition indicate laminar flow to be reaching to almost the aft end of the leading-edge model for the 0.03 -in. configuration.

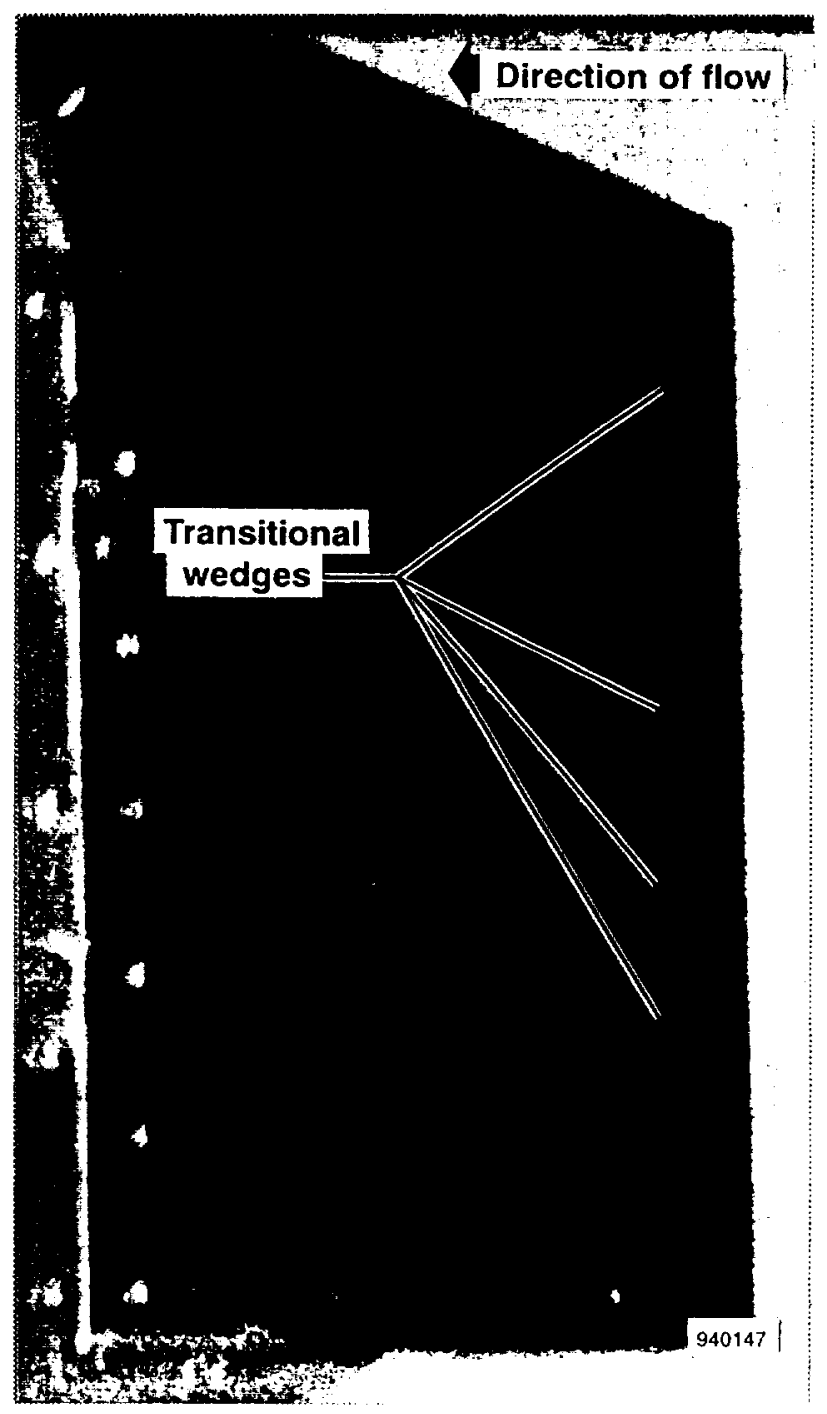

Figure 12. Liquid crystals applied to NLF model; $M=0.7$ and $\mathrm{Re} / \mathrm{ft}=2.0$ million. 


\section{Results for a Two-Gap Configuration}

The next configuration consisted of two 0.06-in. gaps forward and aft of the cover piece. Figures 13 (a) through 13(c) show the hot-film and Stanton-gauge results for Mach number 0.7 and unit Reynolds number 1.5-, 2.0-, and $2.5-\mathrm{million} / \mathrm{ft}$. As can be seen from this figure, the Stanton-gauge results are in complete agreement with the hot-film results.

For a unit Reynolds number of 1.5 million/ $\mathrm{ft}$, the flow remains laminar over the 0.06 -in. gaps but transitions to turbulent flow by the time it reaches station no. 5 . For a unit Reynolds number of 2 million/ $\mathrm{ft}$, the onset of

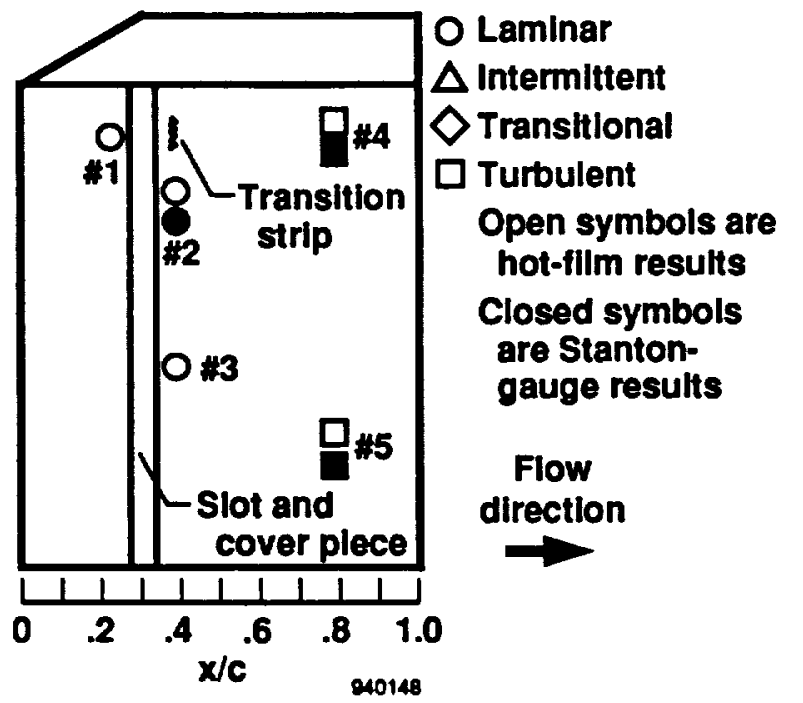

(a) $\mathrm{Re} / \mathrm{ft}=1.5$ million.

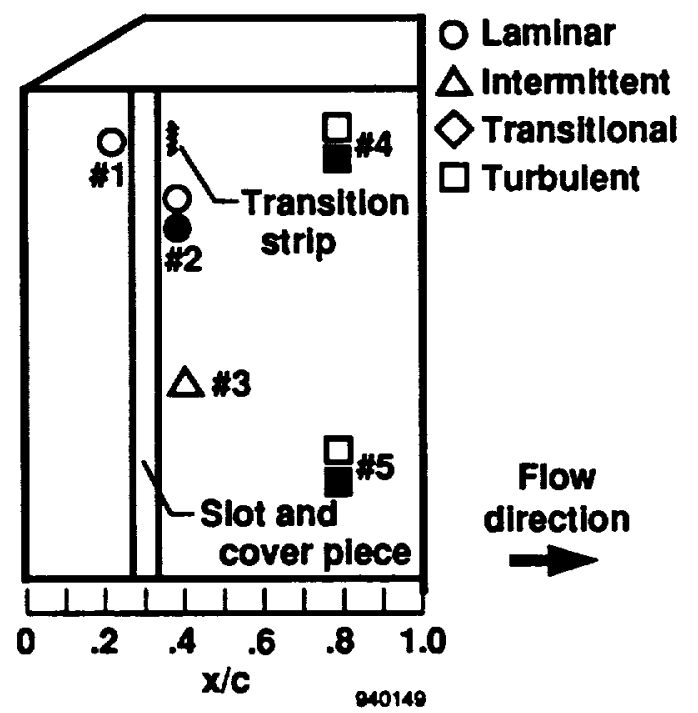

(b) $\mathrm{Re} / \mathrm{ft}=\mathbf{2 . 0}$ million.

Figure 13. Boundary-layer state results for 0.06 -in. forward and aft gaps at $M=0.7$.

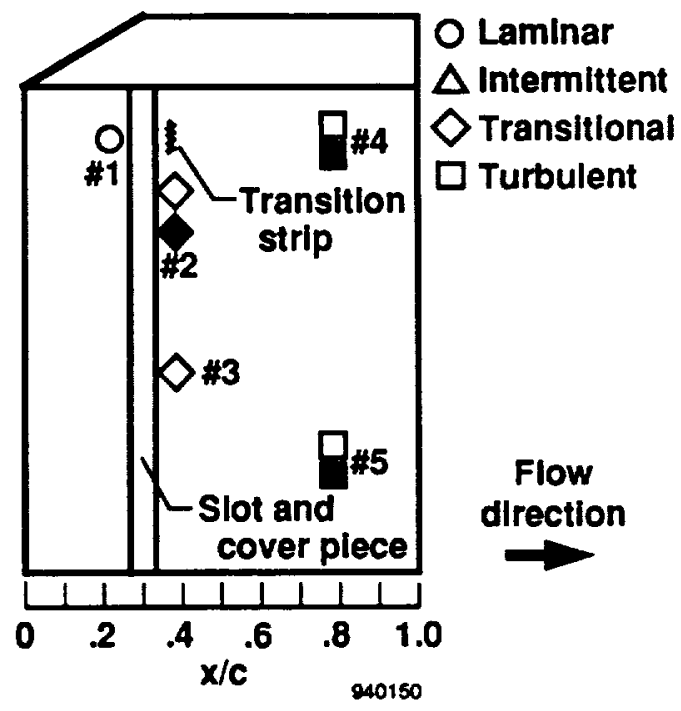

(c) $\mathrm{Re} / \mathrm{ft}=2.5$ million.

Figure 13. Concluded.

turbulence becomes apparent since the flow of hot film no. 3 is now intermittent. The flow becomes transitional at this chord location for unit Reynolds number of $2.5 \mathrm{million} / \mathrm{ft}$.

\section{Results for a Two-Gap-With-Step Configuration}

The third configuration consisted of two 0.06-in. gaps forward and aft of the cover piece and a step of 0.02 in. The addition of this step to the previous configuration caused the flow to completely transition as shown in figures 14(a) and 14(b). These figures show that the flow was transitional at Reynolds number 1.5 million/ $\mathrm{ft}$ and then became completely turbulent immediately aft of the step and gap at Reynolds number of $2.5 \mathrm{million} / \mathrm{ft}$.

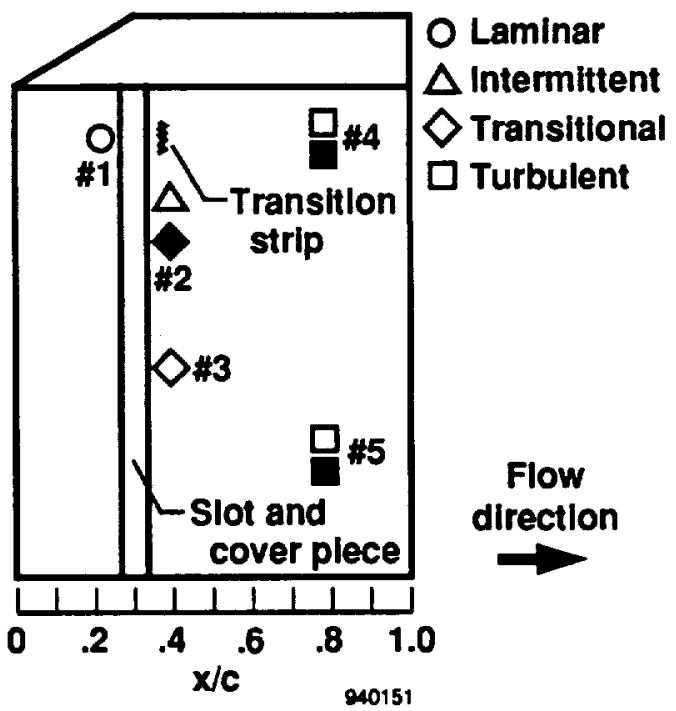

(a) $\mathrm{Re} / \mathrm{ft}=1.5$ million.

Figure 14. Boundary-layer state results for 0.06 -in. forward and aft gaps with 0.02 -in. step at $M=0.7$. 


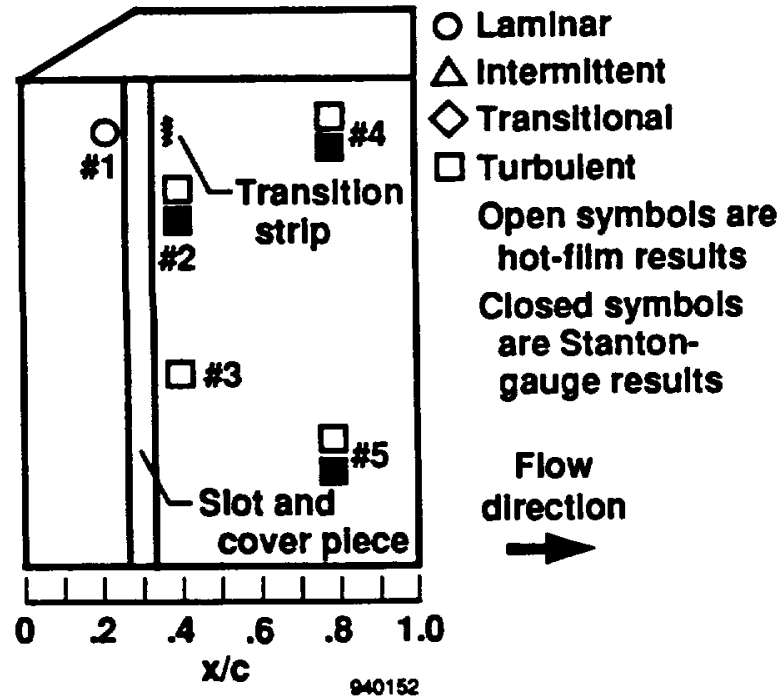

(b) $\mathrm{Re} / \mathrm{ft}=2.5$ million.

Figure 14. Concluded.

The Stanton-gauge results in these figures completely agreed with the hot-film results. With the exception of the results from the 0.03 -in. configuration, the Stanton-gauge results consistently agreed with the hot-film results, proving that they are a viable flight-test technique for determining the state of the boundary layer.

\section{Summary of Results}

In summary, the results of the three configurations shown in this paper were illustrative of the different ways two-dimensional disturbances can affect the laminar boundary layer. ${ }^{2}$ The first case, the 0.03 -in. gap, was an example of a subcritical condition where transition is unaffected by the disturbance. In the second case, two 0.06-in. gaps, the flow began to be affected by the appearance of turbulent bursts downstream of the disturbance. In the literature, this is defined to be the critical condition. Finally in the third case, two 0.06-in. gaps with a 0.02 -in. step, transition occurred right at the disturbance.

The following summarizes the results of the three configurations tested for Mach number 0.7:

\begin{tabular}{|c|c|}
\hline Configuration & $\mathbf{R e}_{\mathrm{rr}}$ \\
\hline 0.03-in. gap & Not observed \\
\hline Two 0.06-in. gaps & $2.5 \times 10^{6}$ \\
\hline $\begin{array}{l}\text { Two } 0.06 \text {-in. gaps } \\
\text { with } 0.02 \text {-in. step }\end{array}$ & $1.5 \times 10^{6}$ \\
\hline
\end{tabular}

As mentioned earlier, gap and step criteria can be found in references 2 through 4. According to these references, the critical gap length Reynolds number was shown to be 15,000 and the critical step height Reynolds number was
1800. The critical Reynolds number for the 0.03 -in. gap should then be $5.8 \mathrm{million} / \mathrm{ft}$. Unfortunately, data were only obtained up to 2.5 million/ft and transition Reynolds number was not defined for this case.

The critical Reynolds number of the other two configurations could not be compared with any criteria, since no data were found in the literature for successive gap and step combinations as those flight tested here. For a single 0.06-in. gap, however, the critical Reynolds number should be 2.86 million/ft as compared with 2.5 million/ft for two successive 0.06 -in. gaps. For a single 0.02 -in. forward step the critical Reynolds number should be $1.1 \mathrm{mil}$ lion/ft as compared with 1.5 million/ft obtained for a 0.02-in. forward step in combination with two 0.06-in. gaps. These results are encouraging since they at least show that step and gap combinations may not be as alarming as may have been expected. Nonetheless, continued work is clearly necessary to fully investigate the effects of step and gap configurations.

\section{Concluding Remarks}

A viable flight test technique was demonstrated for obtaining step and gap criteria for the leading-edge regions of laminar flow wings. A natural laminar flow leadingedge model was designed and flown on the flight test fixture of the F-104 aircraft. The model was flown at transonic conditions representative of subsonic business jets or light transport aircraft.

Hot films and Stanton gauges were used to determine the state of the boundary layer. With the exception of the results from the 0.03 -in. configuration, the Stanton-gauge results consistently agreed with the hot-film results, proving that they are a viable flight-test technique for determining the state of the boundary layer.

Results from three different step and gap configurations were presented. Maximum laminar flow was achieved over the full observed length of the leading-edge model for a unit Reynolds number range of 1.5 to $2.0 \mathrm{million} / \mathrm{ft}$ for Mach number 0.7. A transitional Reynolds number of 2.5 million/ft was found for the configuration with two 0.06-in.-gaps, and a transitional Reynolds number of 1.5 million/ft was determined for the configuration with two 0.06-in. gaps and a 0.02-in. forward step.

\section{References}

'Drake, Aaron and Robert A. Kennelly, Jr., Selected Experiments in Laminar Flow: An Annotated Bibliography, NASA TM-103989, Dec. 1992.

${ }^{2}$ Holmes, Bruce J., Clifford J. Obara, Glenn L. Martin, and Christopher S. Domack, "Manufacturing Tolerances for Natural Laminar Flow Airframe Surfaces," SAE Paper 850863, 1985. 
3Carmichael, B.H., "Surface Waviness Criteria for Swept and Unswept Laminar Suction Wings," Norair report no. NOR-59-438, Aug. 1959.

"Gerhardt, H.A., "Section 10: Waviness and Surface Smoothness Criteria," in "Final Report on LFC Aircraft Design Data Laminar Flow Control Demonstration Program," Norair report no. NOR-67-136, June 1967.

${ }^{5}$ Meyer, Robert R., Jr., A Unique Flight Test Facility: Description and Results, NASA TM-84900, 1982.

'Chiles, Harry R.; and J. Blair Johnson, Development of a Temperature-Compensated Hot-Film Anemometer System for Boundary-Layer Transition Detection on HighPerformance Aircraft, NASA TM-86732, Aug. 1985.

'East, L.F., "Measurement of Skin Friction at Low Subsonic Speeds by the Razor-Blade Technique," Aero. Res. Counc. London, R\&M 3525, Aug. 1966.
${ }^{8}$ Meyer, R.R., Jr., and E.T. Schneider, "Real-Time Pilot Guidance System for Improved Flight Test Maneuvers," AIAA-83-2747, Nov. 1983.

${ }^{9}$ Kennelly, Robert A., Jr., "Improved Method for Transonic Airfoil Design-by-Optimization," AIAA-83-1864, July 1983.

${ }^{10}$ Bradshaw, P. and N. Gregory, "The Determination of Local Turbulent Skin Friction from Observation in the Viscous Sub-layer," Aero. Res. Coun. London, R\&M 3202, Mar. 1959.

"Murphy, John and Jeff Trosin, "IBL User's Guide," Sterling Federal Systems, Inc., Project TN-92-8006-000, Tech. Note 46, Palo Alto, CA, Jan. 1992.

${ }^{12}$ Smith, S., "The Use of Liquid Crystals for Surface Flow Visualization," AIAA 90-1382, June 1990. 



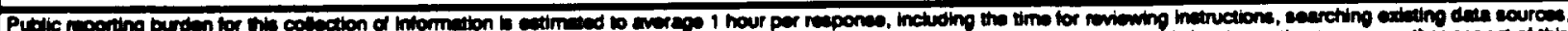

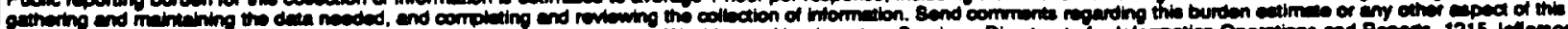
colnction of thorm tion, including aun

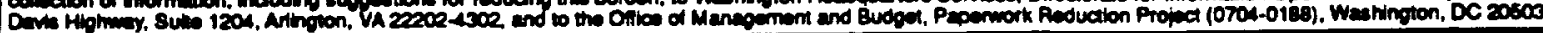

\begin{tabular}{|l|l}
\hline 1. AGEMCY USE ONLY (Leav blank) & $\begin{array}{r}2 \text { REPOAT DATE } \\
\text { August } 1994\end{array}$ \\
\hline
\end{tabular}

3. REPOAT TYPE AND DATES COVERED Technical Memorandum

4. TITL AND SUBTILE 5. FUNDING NUMBERS

Transonic Flight Test of a Laminar Flow Leading Edge With Surface Excrescences

6. AUTMOR(S)

Fanny A. Zuniga (NASA Dryden), Aaron Drake (Stanford University),

Robert A. Kennelly, Jr., and Dennis J. Koga (NASA Ames), and

Russell V. Westphal (Washington State University at Tri-Cities)

7. PERFOAMING ORCAMIZATION NAME(S) AND ADORESS(ES)

NASA Dryden Flight Research Center

P.O. Box 273

WU 505-59-10

Edwards, California 93523-0273

9. SPONSOAINCNONOTOAINO AOENCY NAME(8) AND ADDRESS(ES)

10. SPONSOANOMONITORING ACENCY REPOFT NUMBER

National Aeronautics and Space Administration

Washington, DC 20546-0001

NASA TM-4597

11. SUPPLENENTARY NOTES

This was originally prepared as AIAA-94-2142 for the 6th Biennial Flight Test Conference, Colorado Springs, CO, June 20-23, 1994.

12. OSTRIDUTOOVAVALABIUTY STATEMEMT

12b. DASTRIBUTION CODE

Unclassified—Unlimited

Subject Category 02

12. ADsTRACT (Maximum 200 wordo)

A fight experiment, conducted at NASA Dryden Flight Research Center, investigated the effects of surface excrescences, specifically gaps and steps, on boundary-layer transition in the vicinity of a leading edge at transonic flight conditions. A natural laminar flow leading-edge model was designed for this experiment with a spanwise slot manufactured into the leading-edge model to simulate gaps and steps like those present at skin joints of small transonic aircraft wings. The leading-edge model was flown with the flight test fixture, a lowaspect ratio fin mounted beneath an F-104G aircraft. Test points were obtained over a unit Reynolds-number range of 1.5- to 2.5-million/ft and a Mach-number range of 0.5 to 0.8 . Results for a smooth surface showed that laminar flow extended to approximately 12 in. behind the leading edge at Mach number 0.7 over a unit Reynolds-number range of 1.5- to 2.0-million/ti. The maximum size of the gap-and-step configuration over which laminar flow was maintained consisted of two 0.06-in. gaps with a 0.02-in. step at a unit Reynolds number of 1.5 million/tt.

\section{WUDECT TERMS}

Boundary-layer transition, Hot films, Laminar flow, Stanton gauge measurements, Surface excrescences

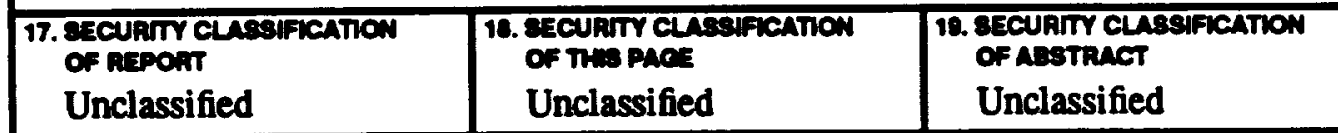

\begin{tabular}{|c|}
\hline $\begin{array}{l}\text { 18. NUMBEA OF PACES } \\
16\end{array}$ \\
\hline $\begin{array}{l}\text { 16. PAICE COOE } \\
\text { AO3 }\end{array}$ \\
\hline 20. UMTATION OF ABgtaACT \\
\hline Unlimited \\
\hline
\end{tabular}

